\title{
Solar-driven sodium thermal electrochemical converter coupled to a Brayton heat engine: Parametric optimization
}

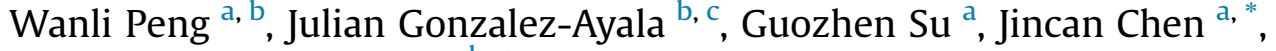 \\ Antonio Calvo Hernández b, c \\ a Department of Physics, Xiamen University, Xiamen, 361005, People's Republic of China \\ b Departamento de Física Aplicada, Universidad de Salamanca, 37008, Salamanca, Spain \\ c Instituto de Física Fundamental y Matemáticas, Universidad de Salamanca, 37008, Salamanca, Spain
}

\section{A R T I C L E I N F O}

\section{Article history:}

Received 9 June 2020

Received in revised form

10 September 2020

Accepted 19 September 2020

Available online 21 September 2020

\section{Keywords:}

Solar collector

Sodium thermal electrochemical converter

Brayton heat engine

Irreversible loss

Performance characteristic

Parametric optimization

\begin{abstract}
A B S T R A C T
A novel high-efficiency device comprised of three subsystems, a solar collector, a sodium thermal electrochemical converter, and a non-recuperative Brayton heat engine, is modeled by taking into account the main internal and external irreversibility sources. The model extends previous works in which the heat waste of the electrochemical converter is used as heat input in a Brayton gas turbine to study its performance and feasibility when a solar energy input is added. The operative working temperatures of three subsystems are determined by energy balance equations. The dependence of the efficiency and power output of the overall system on the solar concentration ratio, the current density, the thickness of the electrolyte, and the adiabatic pressure ratio (or temperature ratio) of the Brayton cycle is discussed in detail. The maximum efficiencies and power output densities are calculated and the states of the maximum efficiency-power density are determined under different given solar concentration ratios. The parametric optimum selection criteria of a number of critical parameters of the overall system are provided and the matching problems of the three subsystems are properly addressed. It is found that under a solar concentration around 1350, the maximum efficiency and power output density of the proposed hybrid system can reach, respectively, $29.6 \%$ and $1.23 \times 10^{5} \mathrm{~W} / \mathrm{m}^{2}$. These values amount approximately $32.7 \%$ and $156 \%$ compared to those of the solar-driven sodium thermal electrochemical converter system without the bottoming Brayton cycle. The Pareto front obtained from numerical multiobjective and multi-parametric methods endorses previous findings.
\end{abstract}

(c) 2020 Elsevier Ltd. All rights reserved.

\section{Introduction}

The sunlight is the greatest source of energy in the world compared with the other common energy sources including the natural gas, coal, and oil. It has obvious advantages such as renewable, free, clean, and long term available [1-3]. Solar energy power systems use the heat produced by collectors to drive some power systems such as Brayton-like gas turbines [4-7], Carnot-like heat engines [8-10], thermionic generators [11-13], thermophotovoltaic cells [14-16], and thermoelectric generators [17-20]. The sodium thermal electrochemical converter (Na-TEC) [also named as the alkali-metal thermal electric converter (AMTEC)] is becoming now-days as a useful power system that generates electricity by

\footnotetext{
* Corresponding author.

E-mail addresses: jcchen@xmu.edu.cn (J. Chen), anca@usal.es (A.C. Hernández).
}

driving sodium ions [21-24]. For example, Cole et al. [21] described the basic operating principles of the Na-TEC; Underwood et al. [22] proposed a new arrangement incorporating internal cells connected in series; Lodhi et al. [23] studied the influence of the electrode materials on the power output degradation showing a performance of the sodium cell up to $77 \%$ when selected materials are used [17,24].

Na-TEC cells are high efficiency devices allowing an appropriate coupling with a variety of heat or fuel sources. In this line, Wu et al. [25] studied an integrating device composed of a parabolic solar collector and a Na-TEC cell; Chivington et al. [26] developed a new conceptual design for a system converting solar energy to electricity with a Na-TEC for spacecraft; Johnson et al. [27] designed and integrated a solar Na-TEC power system with an advanced global positioning satellite; Kotaro [28] studied and analyzed a preliminary design of the solar-driven system with the Na-TEC; Hendricks et al. [29] displayed the crucial aspects of a radial Na-TEC cell 


\begin{tabular}{|c|c|c|c|}
\hline \multicolumn{2}{|c|}{ Nomenclature } & $T_{i}$ & temperature of the working substance \\
\hline$A_{A}$ & area of the absorber, $\mathrm{m}^{2}$ & $T_{0}$ & environment temperature, $\mathrm{K}$ \\
\hline$A_{E}$ & electrode area on BASE tube, $\mathrm{m}^{2}$ & $V_{a c}$ & over potential difference, $\mathrm{V}$ \\
\hline$B$ & a coefficient, $\mathrm{AK}^{1 / 2} / \mathrm{P}_{\mathrm{a}} / \mathrm{m}^{2}$ & $V_{R}$ & ionic BASE voltage, $\mathrm{V}$ \\
\hline Cc & speed of light, $\mathrm{m} / \mathrm{s}$ & $x$ & adiabatic temperature ratio \\
\hline$c_{C}$ & thermal capacitance rate, $\mathrm{J} / \mathrm{K}$ & $z$ & radiation reduction factor \\
\hline$c_{P}$ & molar specific heat, J/mol/K & & \\
\hline$c_{L}$ & thermal conductance, $\mathrm{J} / \mathrm{K}$ & \multicolumn{2}{|c|}{ Greek symbols } \\
\hline$D$ & thickness, m & $\alpha$ & spectral absorbance $\varepsilon$ effectiveness \\
\hline$F$ & Faraday constant, $\mathrm{C} / \mathrm{mol}$ & $\lambda$ & radiation wavelength \\
\hline G & pressure loss geometric factor & $\gamma$ & adiabatic coefficient \\
\hline$J$ & current density, $\mathrm{A} / \mathrm{m}^{2}$ & $\eta$ & efficiency \\
\hline$h$ & Planck constant, J s & $\eta_{0}$ & optical efficiency \\
\hline$K_{B}$ & Boltzmann constant, $\mathrm{J} / \mathrm{K}$ & $\eta_{S}$ & efficiency of solar collector \\
\hline$L$ & atent heat, $\mathrm{J} / \mathrm{g}$ & $\mu$ & an electrolyte coefficient, $\mathrm{m}^{2}$ \\
\hline$M$ & molecular weight, g/molPOD, $\mathrm{W} / \mathrm{m}^{2}$ & $\sigma$ & Stefan-Boltzmann constant, $\mathrm{W} / \mathrm{m}^{2} / \mathrm{K}^{4}$ \\
\hline$p_{1}$ & process $4-1$ pressure, $\mathrm{P}_{\mathrm{a}}$ & & \\
\hline$p_{2}$ & process $2-3$ pressure, $P_{a}$ & \multicolumn{2}{|c|}{ Subscripts } \\
\hline$P$ & power output, $\mathrm{W}$ & $12 / 34$ & isentropic compression/expansion \\
\hline$p_{\text {sat }}$ & saturation vapor pressure, $\mathrm{P}_{\mathrm{a}}$ & $\mathrm{A} / \mathrm{B}$ & NA-TEC/BHE $1,2,3,4,2 s, 4 s$ \\
\hline$\Delta p_{c d}$ & pressure loss, $\mathrm{P}_{\mathrm{a}}$ & $\max$ & maximum \\
\hline$q_{C / H}$ & $\begin{array}{l}\text { heat flows from the condenser/absorber, } \mathrm{W} q_{\text {in }} \\
\text { incoming solar energy, } \mathrm{W}\end{array}$ & \multicolumn{2}{|c|}{ Abbreviations } \\
\hline$q_{L 1}$ & thermal loss, $\mathrm{W}$ & AMTEC & alkali metal thermal electric converter \\
\hline$q_{L 2}$ & heat leak rate, $\mathrm{W}$ & BASE & $\beta^{\prime \prime}$-alumina solid electrolyte \\
\hline$q_{R}$ & reflection loss, $\mathrm{W}$ & ME & maximum efficiency \\
\hline$q_{s}$ & solar radiance heat flow, $\mathrm{W} / \mathrm{m}^{2}$ & MPOD & maximum POD \\
\hline$q_{0}$ & heat flow from the working substance, $\mathrm{W}$ & Na-TEC & odium thermal electrochemical converter \\
\hline$R$ & gas constant, $\mathrm{J} / \mathrm{mol} / \mathrm{K}$ & POD & power output density \\
\hline$r_{p}$ & pressure ratio & TEG & thermoelectric generator \\
\hline$T_{C}$ & condenser temperature, $\mathrm{K}$ & & \\
\hline
\end{tabular}

design in solar systems to achieve high cell performance; Peng et al. [30] established an integrated device comprising a solar collector and a Na-TEC, discussing the influence of key parameters on the whole device performance. Since the exhaust heat temperature of a typical Na-TEC cell is still high, there is room for improvement by means of heat waste recovering. In this sense, there are proposals for hybrid systems where the Na-TEC cell is coupled with tripleeffect absorption refrigeration [31], thermoelectric generator [32,33], or irreversible Brayton power cycle [34].

On the other side, Brayton-like cycles have been extensively analyzed and optimized under different strategies and models [35-37]. So, Roco et al. [35] investigated the optimum performance of a regenerative Brayton-cycle coupled to external heat thermal baths including external and internal irreversibilities. Ust et al. investigated the ecological performance of an endoreversible [36] and irreversible [37] regenerative Brayton heat engine (BHE). Nowadays, studies still exhibit the wide versatility of the Brayton cycle: Durante et al. [38] presented a realistic Brayton cycle working as an externally fired gas turbine fueled with biomass, Guo et al. [39] proposed a storage system composed of a Brayton cycle and a reverse Brayton cycle, Sharan et al. [40] reported that the Brayton cycle with supercritical carbon dioxide presents a higher efficiency compared to the Rankine cycle. As a straightforward consequence of the above, it can be stated that closed and open cycles in BHE technology are amenable to be used with a variety of energy sources coming from not just high-quality fuels.

In a previous paper [34], a configuration in which the heat waste of Na-TECs is used as the heat input in a BHE was studied. In this paper, the main aim is to further extend this study for a solarized
Na-TEC plant in order to study its performance and feasibility when hybridized with a renewable energy input. In particular, the goal of this paper is twofold: a) to establish a creative integrated device comprised of a solar collector, a Na-TEC, and an irreversible nonregenerative BHE, including external and internal irreversibilities, and b) to investigate its whole optimum performance on the basis of the key parameters of each subsystem. Goals a) and b) are accomplished in section 2, where the performance regimes of maximum efficiency (ME), maximum power output density (MPOD), and maximum efficiency-power (defined as the product of efficiency and power) are analyzed for the overall system. Section 3 contains a detailed discussion of numerical results of the optimum ranges of the main parameters involved for different solar concentration ratios and the optimization of the electrolyte thickness. Section 4 contains a detailed discussion on the optimum ranges of the main parameters involved for different solar concentration ratios, along with the comparison of the obtained values for ME and MPOD regimes with other Na-TEC-based hybrid systems reported in the literature. Section 5 is devoted to give a complementary perspective on the overall system using a multi-objective and multi-parametric optimization based on the Pareto front and the associated space of parameters. Finally, a brief summary is presented in Section 6.

\section{The description of a solar-driven Na-TEC-Brayton system}

The integrated system, shown in Fig. 1 (a), is mainly composed of a solar collector, a Na-TEC cell, and a BHE power cycle. The detailed schematics of the Na-TEC cell and BHE cycle are displayed in Fig. 1 
161
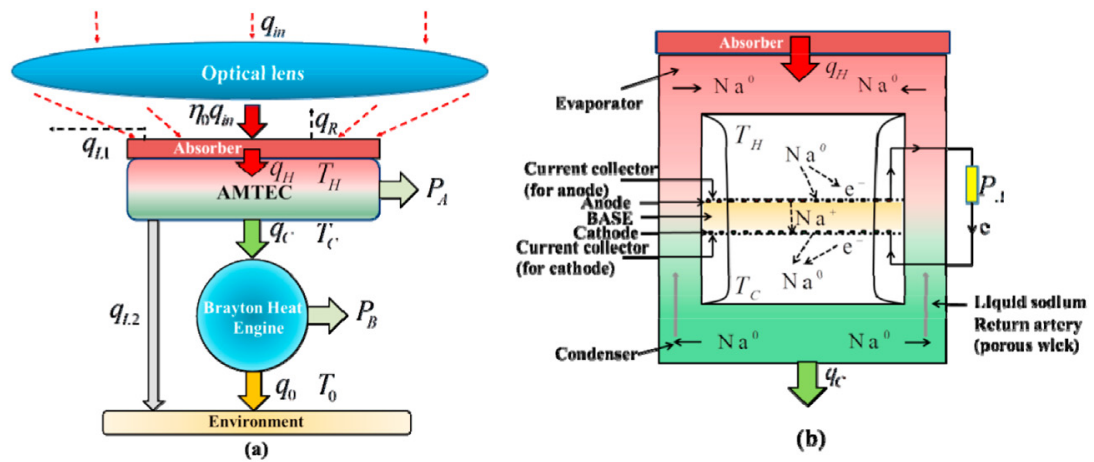

(b)

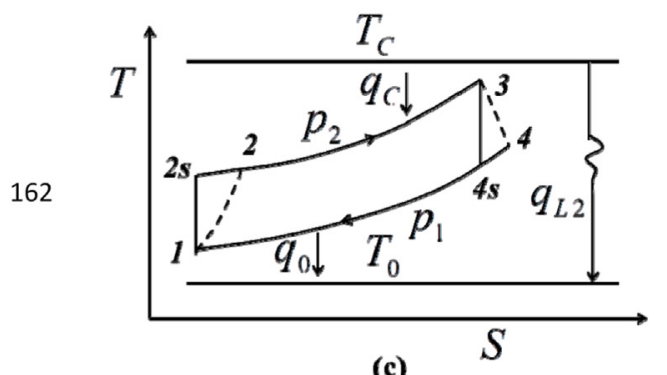

(c)

Fig. 1. The skets of the proposed three-stage device (a) and of the Na-TEC cell (b). In (c) the T-S cycle of a BHE.

(b) and (c), respectively.

The main body of the whole device is the Na-TEC subsystem; see Fig. 1 (b). Briefly, it is mainly comprised by several connected $\beta^{\prime \prime}$-alumina solid electrolyte (BASE) tubes working as a selective barrier to the medium because of its higher ion conductivity in comparison with its electronic conductivity. Ionization of sodium atoms at the hot side becomes as a consequence of the pressure and temperature differences across BASE. Sodium ions diffuse through the BASE to the cathode side while isolated electrons are collected at the anode and they circulate through the external circuit, producing electrical work on the external load. Next, electrons and sodium ions recombine at the surface between BASE and cathode. From a thermal point of view, a Na-TEC cell works between a hightemperature surface (ranging between $900 \mathrm{~K}$ and $1300 \mathrm{~K}$ ) which acts as an evaporator for the high pressure sodium vapor entering the anode, and a low-temperature area (ranging between $400 \mathrm{~K}$ and $800 \mathrm{~K}$ ) acting as a condenser for the low pressure sodium vapor exiting the cathode. Energetically, the temperature of the condenser plays a key role since at that high temperature heat could be released directly to the environment (thus provoking an unvoidable thermal damage) or be recycled by the coupling of the Na-TEC to an additional bottoming power system.

In [34] a BHE was used as a gas turbine bottoming cycle because of its wide versatility both in the used working fluids and multistep arrangements and, very specially, because of it allows its use in a broad variety of energy sources. Also, in these cycles the main internal irreversibilities are well characterized in terms of the compressor and turbine isentropic efficiencie. In Refs. [34] it was reported the suitability of a one-step and non-recuperative BHE with small pressure ratios to work with the required pressurized working fluid using the low grade heat coming from the Na-TEC condenser at temperature $\mathrm{T}_{\mathrm{C}}$; see Fig. 1 (c). Note here as the BHE works in between the hot source given by the condenser, absorbing a $q_{C}$ heat flow and delivering a $q_{0}$ heat flow at a low source at ambient temperature $T_{0}$. Heat leak in the BHE device is taken into account by means of the $q_{L 2}$ heat flow into the atmosphere. In the temperature-entropy diagram in Fig. 1 (c), the main processes of the non-regenerative BHE are detailed. Steps 2-3 (at constant pressure $p_{2}$ ) and 4-1 (at constant pressure $p_{1}$ ) stand for the heat absorption and releasing processes, respectively. Steps $1-2(1-2 \mathrm{~s})$ and 3-4 (3-4s) denote the irreversible (reversible) adiabatic compression and expansion processes accounted for the corresponding isentropic efficiencies (see below Eq (8)).

The third, and most novel part in this work, is the additional consideration of the solar device at the topping of the Na-TEC cell, in order to provide the absorber with enough concentrated solar energy to drive the Na-TEC cell. Note in Fig. 1 (a) how the solar collector consists of a heat absorber and an optical lens. $q_{\text {in }}$ denotes the incoming solar energy and $\eta_{0}$ stands for the optical efficiency. $q_{R}$ and $q_{L 1}$ indicate, respectively, the reflection and thermal losses of the absorber. Is out of the scope of this paper to give technical details about the solar subsystem and the type of concentration device used [7] (tower plant, parabolic trough, parabolic dish, and so on). Instead, a simple model for the concentrating solar system is provided in order to be able to obtain analytical closed expressions for the overall plant efficiency depending just on a few significant parameters. The key point in our model is to get by means of concentrated solar energy the temperature range needed by the Na-TEC cell (between $900 \mathrm{~K}$ and $1300 \mathrm{~K}$ ). Thus, it is considered a generic model (see details in subsection 2.1) already tested in Ref. [30] where the useful energy provided by the solar collector is the difference between the energy transmitted $q_{\text {in }}$ to the receptor and the conduction and convection losses generically accounted by the heat flows $q_{R}$ and $q_{L 1}$.

According to above considerations, the resulting net power 
output comes from two ways: most of thermal energy from the absorber $q_{H}$ is transferred to the NA-TEC cell working between the evaporator and condenser temperatures $[21,41]$ to generate a first power $P_{A}$; then, the BHE working between the condenser temperature and the environment gives a second power output $P_{B}$. Also note the versatility of the proposed model: As particular cases it could give the performance of a solarized BHE power plant working between the solar collector temperature and the environment if the NA-TEC cell is absent and amenable to be hybridized with an external combustion chamber [6]; or the performance of a pure solar-driven NA-TEC cell working between the evaporator and condenser temperatures [30] if the BHE is absent. In the discussion presented in Sec. 6 a comparison among the optimized power output and efficiency of some different configurations is presented.

\subsection{Mathematical model}

\subsubsection{The efficiency of a solar collector}

According to Fig. 1 (a), the efficiency $\eta_{S}$ of the solar collector can be written as [42]. considered as a representative value of a sunny day at PLACE on DATE [43]), $\lambda$ is the radiation wavelength, $h$ is the Planck constant, $c$ stands for the speed of light, $K_{B}$ is the Boltzmann constant, $A_{A}$ denotes the upper surface area of the absorber, and $\alpha(\lambda)$ represents the spectral absorbance of the absorber surface.

2.1.2. The efficiency of a sodium thermal electrochemical cell

As noted above, the Na-TEC is an emerging power conversion technology with some intrinsic advantages such as the long-life operation, reliability, and high efficiency [41]. Under the electrochemical potential gradient established by a sodium pressure difference across the $\beta^{\prime \prime}$-alumina solid electrolyte (BASE), the sodium cations are driven through the BASE membranes to the cathode. At the same time, the electrons circulate through the external load in which power is produced and then they recombine with the sodium cations at the cathode/BASE interface. The neutral sodium releases heat and then condensates to the liquid phase. The liquid sodium is returned to the evaporator region by a porous capillary wick system $[44,45]$. Taking into account the power output and the heat input, see Fig. 1 (b), its efficiency $\eta_{A}$ is given by Ref. [46],

$\eta_{A}=\frac{P_{A}}{q_{H}}=\frac{J A_{E}\left[\frac{R T_{H}}{F} \ln \left[1+p_{s a t}\left(T_{H}\right) \mu D /\left(R T_{H}\right)\right]-V_{a c}-V_{R}\right]}{J A_{E}\left[\frac{R T_{H}}{F} \ln \left[1+p_{s a t}\left(T_{H}\right) \mu D /\left(R T_{H}\right)\right]-V_{a c}-V_{R}\right]+J A_{E} M L / F+J A_{E} c_{P}\left(T_{H}-T_{C}\right) M / F+A_{E} \sigma\left(T_{H}^{4}-T_{C}^{4}\right) / z}$

$$
\begin{aligned}
\eta_{S} & =\frac{q_{H}}{q_{\text {in }}}=\frac{\eta_{0} q_{\text {in }}-q_{R}-q_{L 1}}{q_{\text {in }}} \\
& =\eta_{0}-\frac{\eta_{0} C \int_{0}^{\infty}[1-\alpha(\lambda)] q_{s}(\lambda) d \lambda+2 \pi \int_{0}^{\infty} \alpha(\lambda) h c^{2} \lambda^{-5}\left[\left[\exp \left(\frac{h c}{\lambda K_{B} T_{H}}\right)-1\right]^{-1}-\left[\exp \left(\frac{h c}{\lambda K_{B} T_{0}}\right)-1\right]^{-1}\right] d \lambda}{C \int_{0}^{\infty} q_{s}(\lambda) d \lambda}
\end{aligned}
$$

where

$$
\begin{aligned}
& q_{\text {in }}=C A_{A} \int_{0}^{\infty} q_{s}(\lambda) d \lambda \\
& q_{R}=\eta_{0} C A_{A} \int_{0}^{\infty}[1-\alpha(\lambda)] q_{s}(\lambda) d \lambda \\
& q_{L 1}=2 \pi A_{A} \int_{0}^{\infty} \alpha(\lambda) h c^{2} \lambda^{-5}\left[\left[\exp \left(\frac{h c}{\lambda K_{B} T_{H}}\right)-1\right]^{-1}-\left[\exp \left(\frac{h c}{\lambda K_{B} T_{0}}\right)-1\right]^{-1}\right] d \lambda
\end{aligned}
$$

In the above equations, $C$ denotes the concentration ratio, $q_{s}(\lambda)$ is the solar irradiance heat flow (an irradiance of $10^{3} \mathrm{~W} / \mathrm{m}^{2}$ is 
where $[25,47-50]$.

$$
\left\{\begin{array}{c}
V_{R}=J D\left[1.62 \times 10^{-5} T_{H} \exp \left(-45.5 / T_{H}\right)+1.55 \times 10^{-7} T_{H} \exp \left(3722 / T_{H}\right)\right] \\
V_{a c}=-\frac{2 R T_{H}}{F} \ln \left[\frac{1}{2}\left[\frac{J^{2} T_{H}}{B^{2} p_{\text {sat }}^{2}\left(T_{H}\right)}+4\right]^{\frac{1}{2}}-\frac{1}{2} \frac{J \sqrt{T_{H}}}{B p_{\text {sat }}\left(T_{H}\right)}\right]+ \\
\frac{2 R T_{H}}{F} \ln \left[\frac{1}{2}\left[\frac{J^{2} \sqrt{T_{H} T_{C}}}{B^{2} p_{\text {sat }}\left(T_{H}\right) p_{\text {sat }}\left(T_{C}\right)}+4\left[1+\frac{\left(1+\frac{3 G}{8 \pi}\right) \sqrt{2 \pi M R T_{H} T_{C}} \frac{J}{F}}{p_{\text {sat }}\left(T_{C}\right) \sqrt{T_{H}}}\right]\right]^{\frac{1}{2}}+\frac{1}{2} \frac{J\left(T_{H} T_{C}\right)^{\frac{1}{4}}}{B \sqrt{p_{\text {sat }}\left(T_{H}\right) p_{\text {sat }}\left(T_{C}\right)}}\right]
\end{array}\right.
$$

$P_{\text {sat }}(T)=10^{9.678-5383.2 / T}$ being the $T$-dependent saturation vapor pressure [47], $V_{R}$ denotes the ionic BASE voltage, $V_{a c}$ is the over potential difference, $J$ stands for the current density of the Na-TEC, $M$ and $L$ denote, respectively, the sodium molecular weight and vaporization latent heat, $A_{E}$ corresponds to the electrode area, $c_{P}$ means the molar specific heat, $z$ indicates the radiation reduction factor, $\sigma$ denotes the Stefan-Boltzmann constant, $F$ is the Faraday constant, $\mu$ denotes a superficial electrolyte coefficient, fx 5 stands for the charge-exchange coefficient, $D$ is the electrolyte thickness, $R$ is the gas constant, and $G$ means a pressure loss geometric factor. What is noteworthy is that the specific relational expression among $T_{H}, \mu, D$, and $T_{C}$ is given by [25].

$\frac{p_{\text {sat }}\left(T_{H}\right)}{1+p_{\text {sat }}\left(T_{H}\right) \mu D /\left(R T_{H}\right)}=p_{\text {sat }}\left(T_{C}\right) \sqrt{\frac{T_{H}}{T_{C}}}$

\subsubsection{The efficiency of the irreversible Brayton heat engine}

As shown in Fig. 1 (c), a non-regenerative irreversible BHE operating between the high temperature $T_{C}$ and the low temperature $T_{0}$ is considered. Taking into account the input and output heat fluxes, its efficiency, $\eta_{B}$, is defined as [51-54]:

$$
\left\{\begin{array}{c}
a_{1}=-\left(1 / \eta_{34}\right)\left[\varepsilon_{0} /\left(1-\varepsilon_{0}\right)\right] T_{0}+\varepsilon_{C}\left(1-1 / \eta_{34}\right) T_{C} \\
a_{2}=-\varepsilon_{C} T_{C} \\
a_{3}=-\left(1 / \eta_{12}\right)\left(1-1 / \eta_{34}\right)\left(1-\varepsilon_{C}\right) \\
a_{4}=-\left(1-\varepsilon_{C}\right)\left(1-1 / \eta_{12}\right)\left(1-1 / \eta_{34}\right) \\
+\left(1-\varepsilon_{C}\right) / \eta_{12}-1 / \eta_{34}\left[1 /\left(1-\varepsilon_{0}\right)\right] \\
a_{5}=\left(1-1 / \eta_{12}\right)\left(1-\varepsilon_{C}\right)
\end{array}\right.
$$

$$
\left\{\begin{aligned}
\eta_{12} & =\frac{T_{2 s}-T_{1}}{T_{2}-T_{1}} \\
\eta_{34} & =\frac{T_{3}-T_{4}}{T_{3}-T_{4 s}} \\
x=\left(\frac{p_{2}}{p_{1}}\right)^{\frac{\gamma-1}{\gamma}} & =r_{p}^{\frac{\gamma-1}{\gamma}}=\frac{T_{2 s}}{T_{1}}=\frac{T_{3}}{T_{4 s}}
\end{aligned}\right.
$$

In the above equations $c_{C}$ indicates the thermal capacitance rate, $\varepsilon_{C / 0}$ means the effectiveness of the hot/cold side of the heat exchanger, $\eta_{12 / 34}$ is the isentropic compression/expansion efficiency [51-54], $T_{i}(i=1,2,3,4,2 s, 4 s)$ denotes the temperature of the working substance at the state $i, x$ is the adiabatic temperature ratio [39], $c_{L}$ denotes the corresponding thermal conductance, $\gamma$ means the adiabatic coefficient, and $r_{p}=\frac{p_{2}}{p_{1}}$ denotes the pressure ratio.

$$
\begin{aligned}
\eta_{B}= & \frac{P_{B}}{q_{C}+q_{L 2}}=\frac{q_{C}-q_{0}}{q_{C}+q_{L 2}} \\
= & \frac{c_{C}\left[\varepsilon_{C} T_{C}-\left(x-1+\eta_{12}\right)\left(\frac{\varepsilon_{C}}{\eta_{12}}\right)\left(\frac{a_{1} x+a_{2}}{a_{3} x^{2}+a_{4} x+a_{5}}\right)-\frac{\varepsilon_{0}}{1-\varepsilon_{0}}\left(\frac{a_{1} x+a_{2}}{a_{3} x^{2}+a_{4} x+a_{5}}-T_{0}\right)\right]}{c_{C} \varepsilon_{C}\left[T_{C}-\left(\frac{x-1+\eta_{12}}{\eta_{12}}\right)\left(\frac{a_{1} x+a_{2}}{a_{3} x^{2}+a_{4} x+a_{5}}\right)\right]+c_{L}\left(T_{C}-T_{0}\right)}
\end{aligned}
$$

where
2.1.4. The efficiency of the overall hybrid device

By using Eqs. (1), (3) and (6), the efficiency $\eta$ and power output $P$ of the whole system can be written, respectively, as: 
Table 1

Standard values of some parameters used in the hybrid system [25,30,48,52].

\begin{tabular}{|c|c|c|c|}
\hline$R(\mathrm{~J} / \mathrm{mol} / \mathrm{K})$ & 8.314 & $L(\mathrm{~J} / \mathrm{g})$ & 4480 \\
\hline$c\left(\mathrm{~m} \mathrm{~s}^{-1}\right)$ & $3 \times 10^{8}$ & $\varepsilon_{C}$ & 0.95 \\
\hline$T_{0}(\mathrm{~K})$ & 300 & $\varepsilon_{0}$ & 0.99 \\
\hline$h(\mathrm{~J} \mathrm{~s})$ & $6.63 \times 10^{-34}$ & $M(\mathrm{~g} / \mathrm{mol})$ & 23 \\
\hline$B\left(\mathrm{~A} \sqrt{\mathrm{K}} / \mathrm{P}_{\mathrm{a}} / \mathrm{m}^{2}\right)$ & 90 & $\eta_{0}$ & 0.9 \\
\hline$F(\mathrm{C} / \mathrm{mol})$ & 96485 & $\eta_{12}$ & 0.85 \\
\hline$G$ & 10 & $\eta_{34}$ & 0.9 \\
\hline$z$ & 50 & $\sigma\left(\mathrm{W} / \mathrm{m}^{2} / \mathrm{K}^{4}\right)$ & $5.67 \times 10^{-8}$ \\
\hline$\mu\left(\mathrm{m}^{2}\right)$ & $10^{7}$ & $c_{L} / c_{C}$ & 0.02 \\
\hline$c_{P}(\mathrm{~J} / \mathrm{mol} / \mathrm{K})$ & 30 & & \\
\hline
\end{tabular}

Table 2

$\eta_{\max , C}, p_{\max , C}, Z_{\max , C}$, and the optimal values of several key parameters for the given values of $C$.

\begin{tabular}{|c|c|c|c|c|c|c|c|c|c|c|c|}
\hline$C$ & $\eta_{\max , C}$ & $\begin{array}{l}p_{\max , C} \\
\left(10^{5} \mathrm{~W} / \mathrm{m}^{2}\right)\end{array}$ & $\begin{array}{l}Z_{\max , C} \\
\left(10^{3} \mathrm{~W} / \mathrm{m}^{2}\right)\end{array}$ & $\begin{array}{l}D_{\eta_{\max }, C} \\
\left(10^{-6} \mathrm{~m}\right)\end{array}$ & $\begin{array}{l}D_{p_{\max }, C} \\
\left(10^{-6} \mathrm{~m}\right)\end{array}$ & $x_{\eta_{\max }, C}$ & $x_{p_{\max }, C}$ & $\begin{array}{l}J_{\eta_{\max , C}} \\
\left(\mathrm{~A} / \mathrm{m}^{2}\right)\end{array}$ & $\begin{array}{l}J p_{p_{\max , c}} \\
\left(\mathrm{~A} / \mathrm{m}^{2}\right)\end{array}$ & $\begin{array}{l}T_{H, \eta_{\max }, C} \\
(\mathrm{~K})\end{array}$ & $\begin{array}{l}T_{H, p_{\max }, C} \\
(\mathrm{~K})\end{array}$ \\
\hline 200 & 0.171 & 1.22 & 4.01 & 3.16 & 1.00 & 1.48 & 1.56 & 3.42 & 5.66 & 980 & 1300 \\
\hline 400 & 0.220 & 1.23 & 13.8 & 2.00 & 1.00 & 1.52 & 1.56 & 3.84 & 5.66 & 1100 & 1300 \\
\hline 600 & 0.247 & 1.23 & 17.5 & 1.59 & 1.00 & 1.54 & 1.56 & 4.04 & 5.66 & 1200 & 1300 \\
\hline 850 & 0.270 & 1.23 & 19.7 & 1.00 & 1.00 & 1.56 & 1.56 & 4.18 & 5.66 & 1280 & 1300 \\
\hline 1100 & 0.286 & 1.23 & 20.9 & 1.00 & 1.00 & 1.56 & 1.56 & 4.18 & 5.66 & 1300 & 1300 \\
\hline 1350 & 0.296 & 1.23 & 21.7 & 1.00 & 1.00 & 1.56 & 1.56 & 4.18 & 5.66 & 1300 & 1300 \\
\hline
\end{tabular}
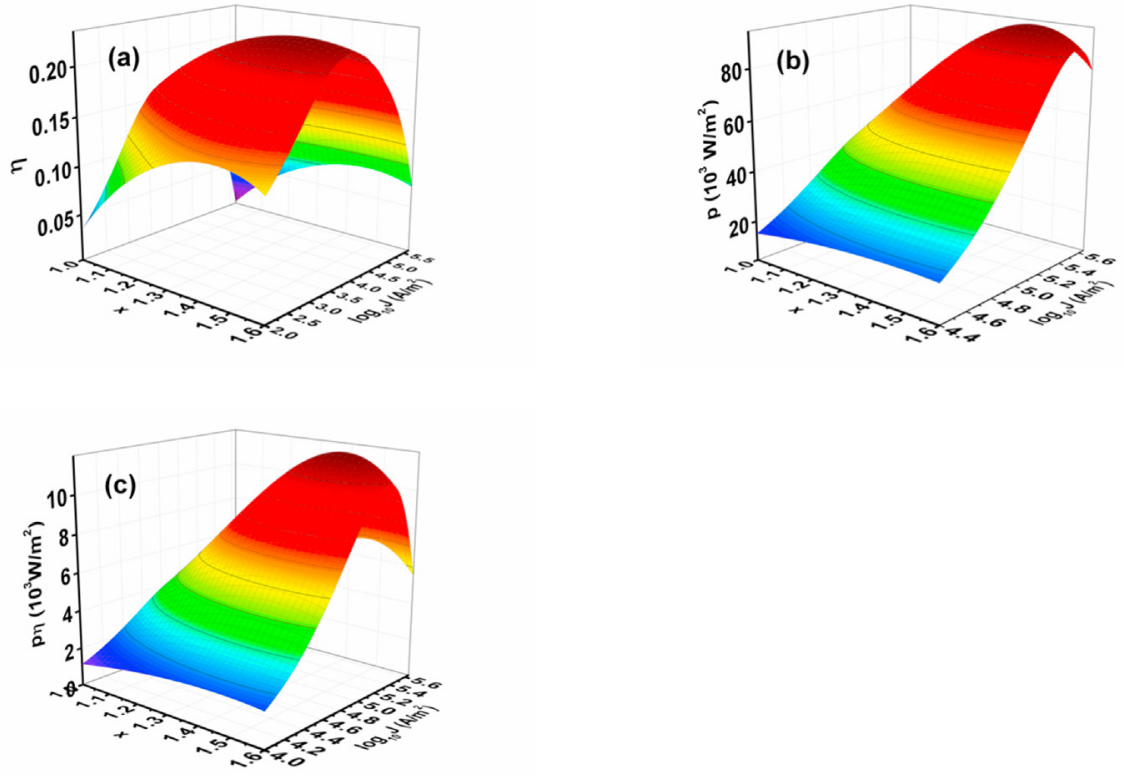

Fig. 2. (a) $p$, (b) $\eta$, and (c) $Z$ as functions of $x$ and $J$ for $D=5 \times 10^{-6} \mathrm{~m}$ and $C=500$, where $T_{H}$ has been optimized.
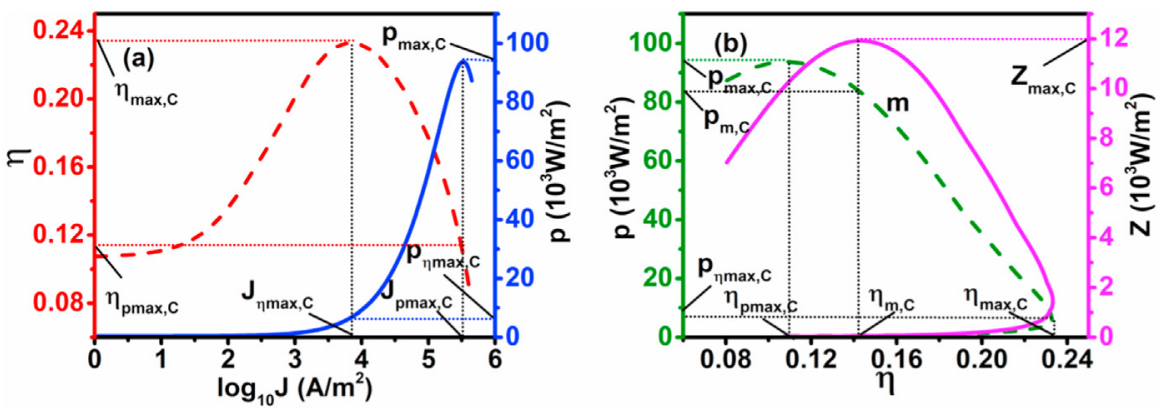

Fig. 3. (a) $\eta$ and $p$ as functions of $J$ and (b) $p$ and $Z=p \eta$ versus $\eta$ for $C=500$ and $D=5 \times 10^{-6} \mathrm{~m}$, where both $x$ and $T_{H}$ is such that it optimizes efficiency and POD. 

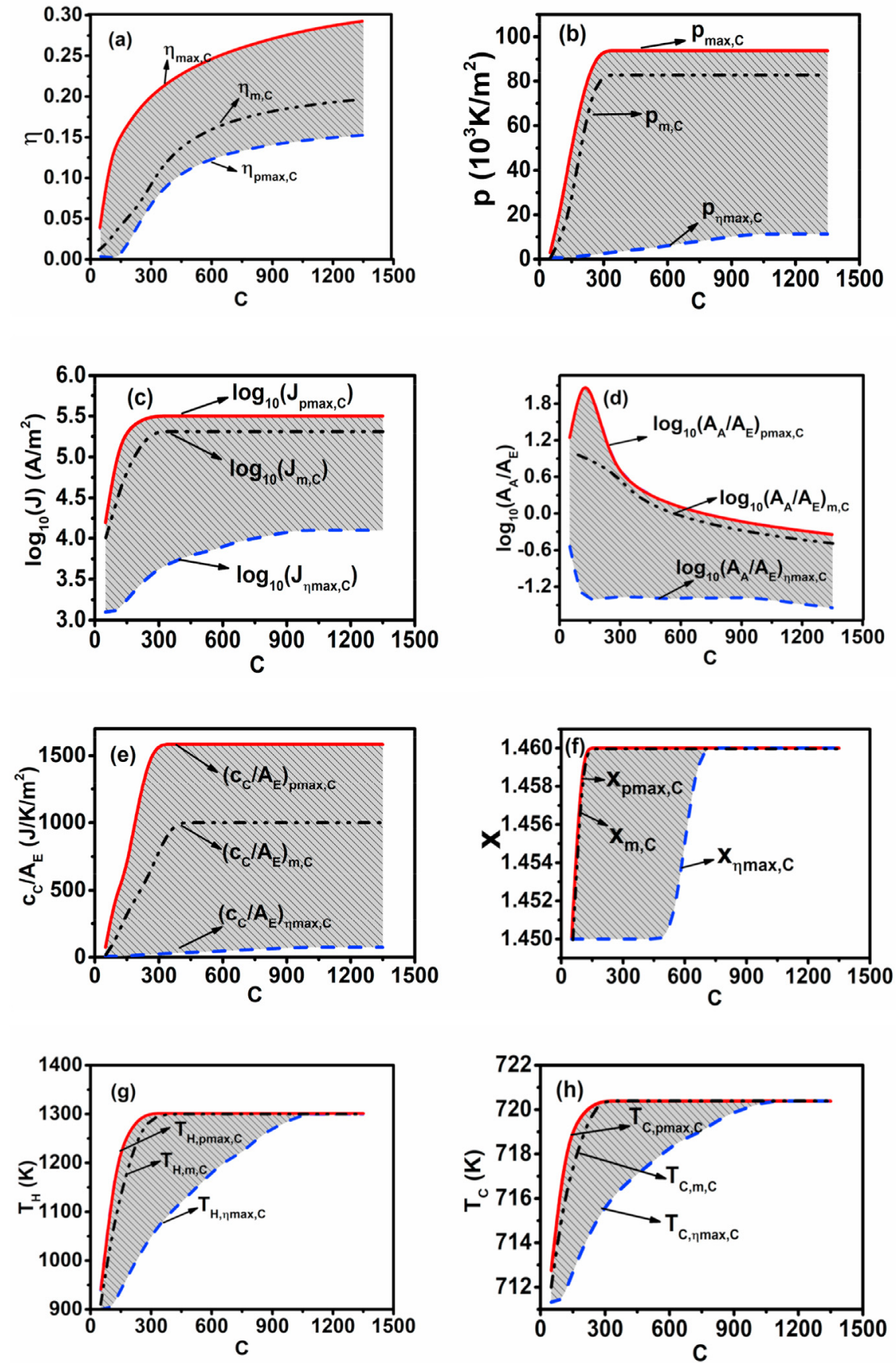

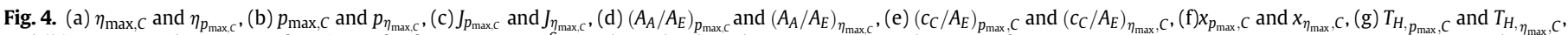

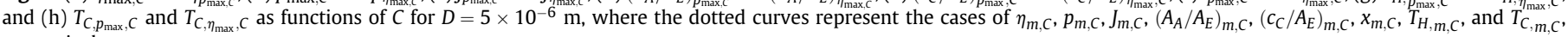
respectively. 

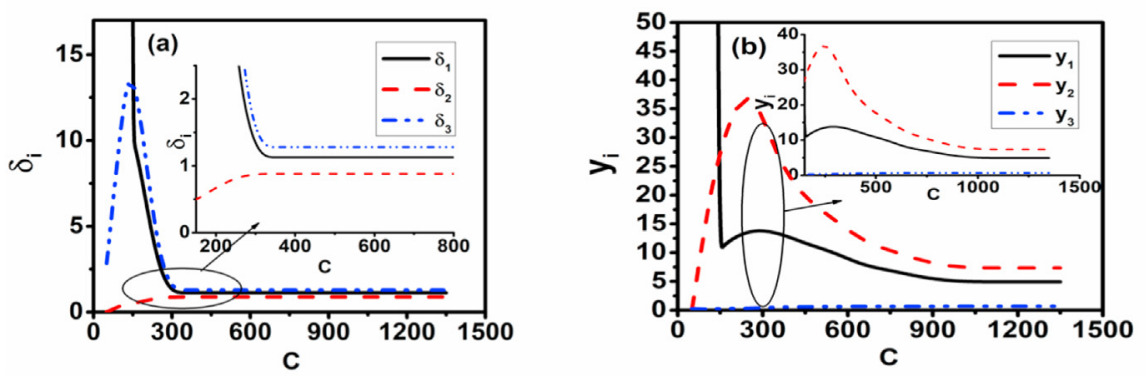

Fig. 5. (a) $\delta_{i}(i=1,2,3)$ and (b) $y_{i}(i=1,2,3)$ as functions of $C$ for $D=5 \times 10^{-6} \mathrm{~m}$.

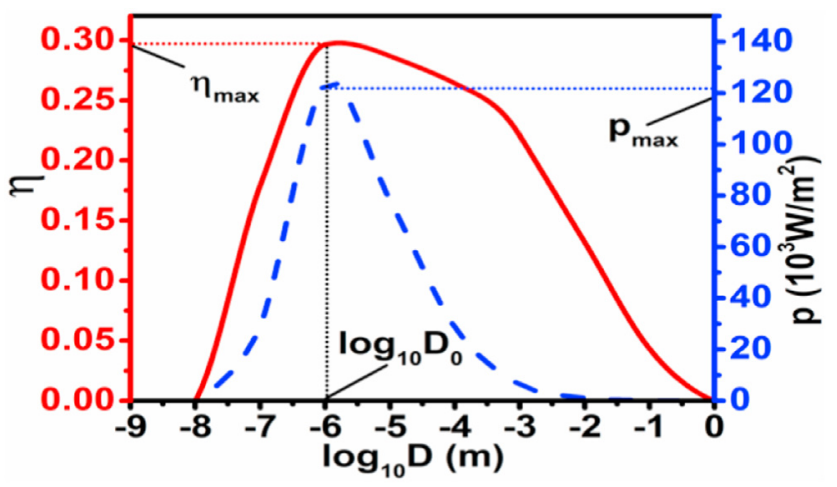

Fig. 6. $\eta$ and $p$ as functions of $D$ for $C=1350$, where $J, x$ and $T_{H}$ have been chose to optimize efficiency and POD.

$\eta=\frac{P}{q_{\text {in }}}=\eta_{S} \eta_{A}+\eta_{S} \eta_{B}\left(1-\eta_{A}\right)$

\section{Results}

3.1. The maximum efficiency and maximum power output density for a given concentration ratio

Eqs. (9) and (10) show that both $\eta$ and $P$ of the whole system depend on some key parameters for each involved subsystem, such as $C, T_{H}, T_{C}, J, x, A_{A} / A_{E}, c_{C} / A_{E}$, and $D$. When $C$ and $D$ are given and $T_{H}$ is chosen to maximize efficiency and power output density (POD) in the range of $900-1300 \mathrm{~K}$, two parameters among $T_{C}, J, x, A_{A} / A_{E}$, and $c_{C} / A_{E}$ may be chosen as independent variables because there are three constraint equations: $q_{H}=\eta_{0} q_{i n}-q_{R}-q_{L 1}, q_{H}-P_{A}=q_{C}+$ $q_{L 2}$, and Eq. (5). If $J$ and $x$ are selected as independent variables and the data in Table 1 are adopted, Eqs. (9) and (10) can be used to generate the 3D-graphs of the efficiency $\eta$ and POD $p=P / A_{E}$ varying with $J$ and $x$, as depicted in Fig. 2 (a) and (b), respectively. Additionally, one can take $\eta p \equiv Z$ (the so-called efficient power regime, first introduced by Stucki in the context of biochemistry [55] and later widely applied in the finite time models of heat engines [56]) as a new objective function and obtain the threedimensional graph of $Z$ varying with $J$ and $x$, as shown in Fig. 2

$$
\begin{aligned}
P & =P_{A}+P_{B}=\eta_{0} q_{\text {in }}-q_{L 1}-q_{R}-q_{L 2}-q_{0} \\
& =J A_{E}\left[\frac{R T_{H}}{F} \ln \left[1+p_{\text {sat }}\left(T_{H}\right) \mu D /\left(R T_{H}\right)\right]-V_{a c}-V_{R}\right]+ \\
& c_{C}\left[\varepsilon_{C} T_{C}-\varepsilon_{C}\left(x-1+\eta_{12}\right)\left(\frac{1}{\eta_{12}}\right)\left(\frac{a_{1} x+a_{2}}{a_{3} x^{2}+a_{4} x+a_{5}}\right)-\frac{\varepsilon_{0}}{1-\varepsilon_{0}}\left(\frac{a_{1} x+a_{2}}{a_{3} x^{2}+a_{4} x+a_{5}}-T_{0}\right)\right]
\end{aligned}
$$

In the following optimized performances of the overall arrangement will be analyzed in terms of the main involved parameters in each subsystem: current density of the Na-TEC cell (J), the thickness of the electrolyte (D), the concentration ratio (C) of the solar collector, and the adiabatic temperature ratio (or compression ratio) of the BHE $x$. First, the available pressure ratios and current density are determined taking as objective functions the overall efficiency and power output density; then, the influence of the concentration ratio and thickness of the electrolyte on these energetic magnitudes is analyzed. Jointly this information gives the optimal values of the key parameters for the overall system as compiled in Table 2. (c). Fig. 2 shows that $\eta, p$, and $Z$ are not monotonical functions of $x$ and $J$, and there exist different optimal values of $x$ and $J$ to maximize $\eta, p$, and $Z$. When $x$ is optimally chosen, the effects of $J$ on both $\eta$ and $p$ are displayed in Fig. 3 (a). $\eta$ and $p$ attains their respective maxima, i.e., $\eta_{\max , C}=0.233$ and $p_{\max , C}=93.8 \times 10^{3} \mathrm{~W} /$ $\mathrm{m}^{2}$, respectively. $p_{\eta_{\max }, C}$ and $\eta_{p_{\max }, C}$ indicate the POD at $\eta_{\max , C}$ and the efficiency at $p_{\max , C}$, respectively. Meanwhile, the optimal ranges of $J, p$, and $\eta$ can be determined as

$$
\begin{aligned}
& J_{\eta_{\max }, C} \leq J \leq J_{p_{\max }, C} \\
& p_{\eta_{\max , C}} \leq p \leq p_{\max , C}
\end{aligned}
$$

and

$\eta_{p_{\max , C}} \leq \eta \leq \eta_{\max , C}$ 
Table 3

The comparison of $\eta_{\max }$ and $p_{\max }$ of several Na-TEC-based hybrid systems.

\begin{tabular}{|c|c|c|c|c|c|c|}
\hline \multirow{2}{*}{ Systems } & \multicolumn{6}{|c|}{ Parameters } \\
\hline & $\eta_{\max }$ & $\begin{array}{l}p_{\max } \\
\left(10^{3} \mathrm{~W} / \mathrm{m}^{2}\right)\end{array}$ & $\begin{array}{l}\text { The percentage increase of } \eta_{\max } \\
\text { compared with Solar- Na-TEC }\end{array}$ & $\begin{array}{l}\text { The percentage increase of } p_{\max } \\
\text { compared with Solar- Na-TEC }\end{array}$ & $\begin{array}{l}\text { The percentage increase of } \eta_{\max } \\
\text { compared with single Na-TEC }\end{array}$ & $\begin{array}{l}\text { The percentage increase of } p_{\max } \\
\text { compared with single Na-TEC }\end{array}$ \\
\hline $\begin{array}{c}\text { Solar-Na- } \\
\text { TEC- } \\
\text { BHE }\end{array}$ & 0.296 & 123 & $32.7 \%$ & $156 \%$ & - & - \\
\hline $\begin{array}{l}\text { Solar-Na- } \\
\text { TEC }\end{array}$ & 0.223 & 48.0 & - & - & - & - \\
\hline $\begin{array}{c}\text { Na-TEC- } \\
\text { BHE } \\
{[34]}\end{array}$ & 0.417 & 116 & - & - & $31.5 \%$ & $142 \%$ \\
\hline Na-TEC & 0.317 & 48.0 & - & - & - & - \\
\hline $\begin{array}{c}\text { Na-TEC- } \\
\text { TEG } \\
{[33]}\end{array}$ & 0.346 & 64.3 & - & - & $9.15 \%$ & $34.0 \%$ \\
\hline
\end{tabular}

Moreover, one can find that $p_{\max , C}$ is much larger than $p_{\eta_{\max }, C}$ and $\eta_{\max , C}$ is much larger than $\eta_{P_{\max , \mathrm{C}}}$. In Fig. 3 (b), $Z_{\max , C}$ is the peak value of $p \eta$ for a given $C$, which corresponds to the state denoted by $m$ on the $\eta \sim p$ characteristic curve [30]. The POD and efficiency on the state point $m$ are described by $p_{m, c}$ and $\eta_{m, C}$, respectively. Fig. 3 (b) shows that the point $m$ lies in between the states of the MPOD and the ME, and $\eta_{m, C}$ and $p_{m, C}$ are, respectively, determined by

$\eta_{p_{\max , C}}<\eta_{m, C}<\eta_{\max , C}$

and

$p_{\eta_{\max , C}}<p_{m, C}<p_{\max , C}$
It can be found that compared to the state of the maximum POD (efficiency), the relative increase of the efficiency (POD) in the state $Z_{\text {max }, C}$ is more outstanding than the relative decrease of the POD (efficiency). Thus, the efficient-power regime acts as a figure of merit yielding power and efficiency in between those of the maximum efficiency and maximum power.

\subsection{Effects of the concentration ratio (C)}

By using Eqs. (3), (6), (9) and (10), the influences of $C$ on the lower and upper boundaries of $\eta, p, J, A_{A} / A_{E}, c_{C} / A_{E}, x, T_{H}$, and $T_{C}$ are displayed in Fig. 4 (a)-(h), respectively. $\eta_{p_{\max }, C}$ and $\eta_{\max , C}, p_{\eta_{\max }, C}$ and $p_{\max , C}, J_{\eta_{\max }, C}$ and $J_{p_{\max }, C},\left(c_{C} / A_{E}\right)_{\eta_{\max }, C}$ and $\left(c_{C} / A_{E}\right)_{p_{\max }, C}, x_{p_{\max }, C}$ and $x_{\eta_{\max }, C}, T_{H, \eta_{\max }, C}$ and $T_{H, p_{\max }, C}$, and $T_{C, \eta_{\max }, C}$ and $T_{C, p_{\max }, C}$ monotonically (a)

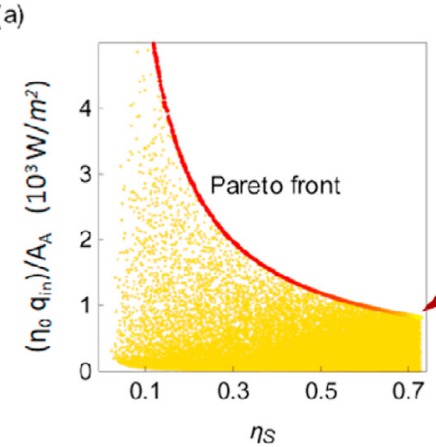

(d)

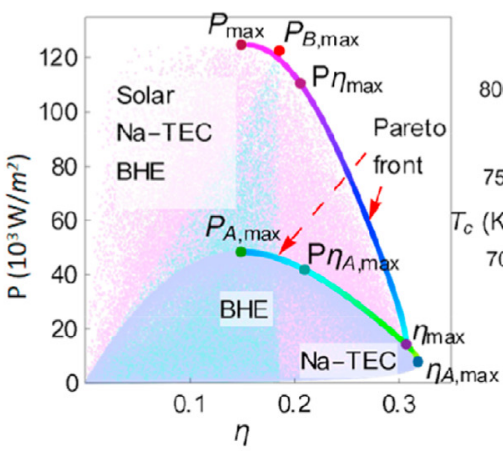

(b) $T_{c}(\mathrm{~K})$

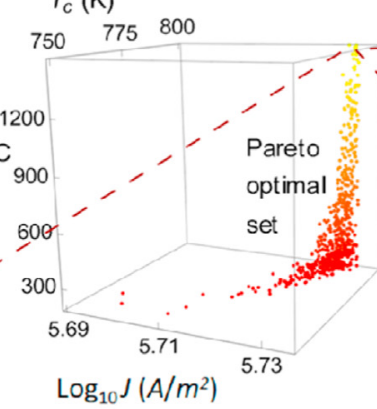

(e)

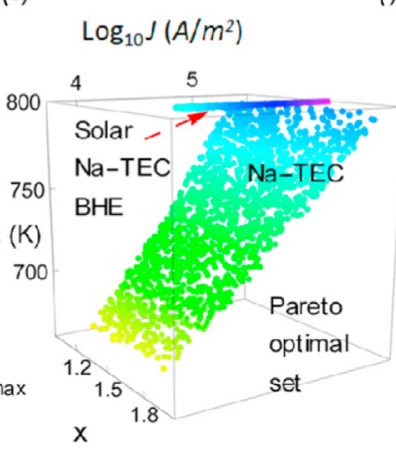

(c)

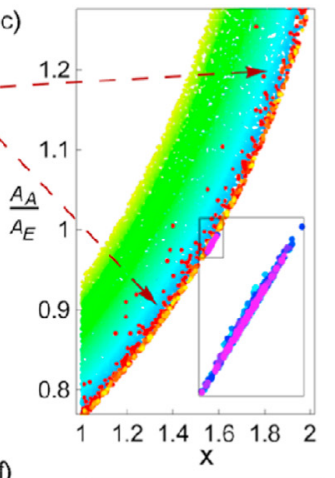

(f)

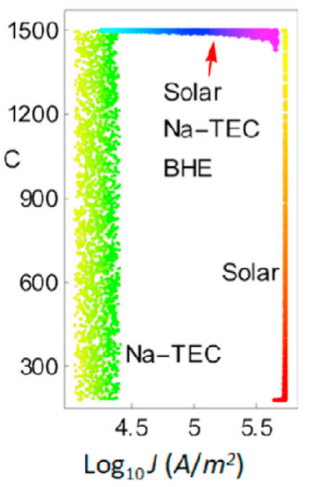

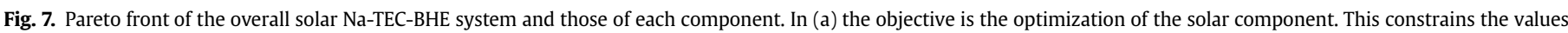

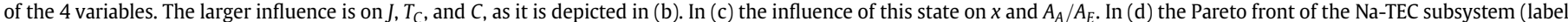

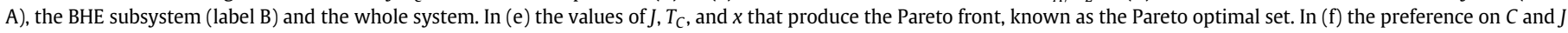
is noticeably different whenever each system is optimized. 
increase as Cincreases, while $\left(A_{A} / A_{E}\right)_{p_{\max . \mathrm{C}}}$ is not a monotonic function of $C$ and $\left(A_{A} / A_{E}\right)_{\eta}$ monotonically decreases as Cincreases. The gray areas stand for the optimum ranges of these parameters, respectively. $p_{\max , C}, \quad J_{p_{\max }, C},\left(c_{C} / A_{E}\right)_{p_{\max }, C}, x_{p_{\max }, C}$, $T_{H, p_{\max }, C}$, and $T_{C, p_{\max }, C}$ increase rapidly in the region of $C<200$; while they keep almost unchanged in the region of $C>200$. Analogously, the influences of $C$ on the parameters on the point $m$ in Fig. 3 (b) are displayed by the dotted curves in the gray regions of Fig. 4. It can be seen clearly that for an arbitrary value of $C$, the point $m$ is closer to the state of the MPOD than that of the ME. Fig. 4 (g) indicates that when $C$ is small, $T_{H}$ is not high enough to drive the Na-TEC cell.

The data in Fig. 4 can be further used to obtain $Z_{\max , C} /$ $\left(p_{\max , C} \eta_{p_{\max , C}} \equiv \delta_{1}, \quad p_{m, C} / p_{\max , C} \equiv \delta_{2}, \quad \eta_{m, C} / \eta_{p_{\max , \mathrm{C}}} \equiv \delta_{3}, \quad Z_{\max , C} /\right.$ $\left(p_{\eta_{\max , C}} \eta_{\max , C}\right) \equiv y_{1}, p_{m, C} / p_{\eta_{\max , C}} \equiv y_{2}$, and $\eta_{m, C} / \eta_{\max , C} \equiv y_{3}$ for different values of $C$, as illustrated in Fig. 5 . It is seen from Fig. 5 (a) that in the region of $C>150, \delta_{2}<1, \delta_{3}>1$, and $\delta_{1}=\delta_{2} \delta_{3}>1$. It can be also seen from Fig. 5 (b) that in the region of $C>150, y_{2}>7.35, y_{3}<1$, and $y_{1}=y_{2} y_{3}>4.93$. It is a remarkable fact that when the concentration ratio is low, i.e., $C \leq 150, \delta_{1}>>1$ and $y_{1}>>1$. This indicates that compared to the ME-state, the optimized state $m$ has obvious advantages for all reasonable values of solar concentration.

\subsection{Optimization of the electrolyte thickness}

Fig. 4 shows that according to practical requirements, different values of $C$ are allowed. For example, when $C=1350$ is chosen, one can further plot the curves of $\eta$ and $p$ varying $D$, as displayed in Fig. 6, where $J, x$, and $T_{H}$ have been chosen to optimize the efficiency and POD. It is observed from Fig. 6 that when $D=D_{0}$, both $\eta$ and $p$ attain simultaneously their respective maxima. What is noteworthy is that the optimal values $D_{\eta_{\max }, C}$ and $D_{\eta_{\max }, C}$ of $D$ at the ME and MPOD are usually different because $q_{\text {in }}$ includes $A_{A}$ and $A_{A} / A_{E}$ is associated with $D$. For an arbitrary reasonable value of $C$, one can calculate $\eta_{\max , C}, p_{\max , C}$, and $Z_{\max , C}$ and the optimal values of several key parameters, as listed in Table 2 .

From data in Table 2 the following points are stressed: (i) It is remarkable that $\eta_{\max , C}$ and $Z_{\max , C}$ are monotonically increasing functions of $C$. Although $p_{\max , C}$ keeps almost unchanged, the maximum power output is also a monotonically increasing functions of $C$ because $\left(A_{E} / A_{A}\right)_{p_{\max , C}}$ increases with the increase of $C$, as shown by the region of $C \geq 200$ in Fig. 4 (d); (ii) In the region of small solar concentration ratios, the difference between $D_{p_{\max }, C}$ and $D_{\eta_{\max }, C}$ is very small and in the region of larger solar concentration ratios, both $D_{p_{\max }, C}$ and $D_{\eta_{\max }, C}$ are the same; (iii) The difference between $x_{p_{\max }, C}$ and $x_{\eta_{\max }, C}$ decreases with the increase of $C$ and it disappear at large solar concentration ratios; (iv) The difference between $J_{p_{\max , C}}$ and $J_{\eta_{\max , C}}$ decreases with the increase of $C$ and tends to a constant for large solar concentration ratios.

\section{Discussion}

Indeed, all above results are meaningful in the coupling of three subsystems to give an optimal design of the whole system. But special mention should be done on the concentration ratio and the temperature $T_{H}$ in the evaporator coming from the solar device. Though the analyzed optimal performance regime requires high concentration ratios, see Fig. 4 (g), what it is also valuable is the following fact: even a moderate concentration ratios (around 300) the $T_{H}$ values are enough to drive the sodium cell in the maximum power regime as can be checked in the last two columns in Table 2 and in Fig. 4 (b). Concentration rates above 300 gives no substancial increasing of $T_{H}$. In other words, the maximum power regime saturates above moderate concentration ratios. Opposite, the maximum efficiency regime requires a noticeable increase in the concentration ratio, see Fig. 4 (a), due to the extra losses by radiation at these temperatures. It is worth to mention that concentration ratios around 300 yielding the needed temperatures in the solar absorber, are available by the recent concentration power plants technologies [57]. In this line, results show the feasibility of the maximum power regime while upper bounds values of efficiency would precise additional minimization of the radiation losses. Besides, an important point is that the size of the BHE is not subtancially modified as the pressure ratio changes are very low in terms of the concentration ratio, as can be checked in Fig. 4 (f) and the numerical values of $x_{p_{\max }, C}$ and $x_{\eta_{\max }, C}$ in Table 2.

For the proposed system, $\eta_{\max }$ and $p_{\max }$ can be compared with the corresponding values expected from a Solar-Na-TEC system without the bottoming Brayton cycle. This comparison is presented in Table 3 for $C=1350$ (see rows 1 and 2 ). It can be seen that under the same solar concentration ratio, the performance of the system is noticeably improved by adding the bottoming Brayton heat engine in order to recover the heat waste delivered by the sodium cell. Again, should be noticed a valuable difference between the maximum efficiency and the maximum power regimes in regards the role played by the concentration ratio. While high concentration ratios $(C=1350)$ are needed to get maximum efficiency as consequence of the monotonic increases in Fig. 4 (a), maximum power does not need such high concentration ratios since a moderate and technically accessible values get the saturated value. In any case the needed pressure ratios in the BHE device remain practically the same.

In the same way, when the solar collector in Fig. 1 is removed and the energy input is considered as another heat sources at temperature $T_{H}$, the previously analyzed Na-TEC-BHE system [34] is recovered. The values of $\eta_{\max }$ and $p_{\max }$ for Na-TEC-BHE and Na-TEC systems with $T_{H}=1300 \mathrm{~K}$ are also listed in Table 3 (see row 3). Once again it is highlighted the efficient use of the BHE using heat waste from the Na-TEC component. This added value is the key fact what makes the combination solar-Na-TEC-BHE very valuable against combinations where the sodium cell is absent. If the sodium cell is removed the resulting solarized Brayton gas turbine could get higher efficiency values but at compression ratios much higher [7] with multistage arrangements and an additional combustion chamber or storage system. In brief, the BHE versatility provides a very efficient use of the heat waste in the sodium cell.

A comparison with the hybrid system discussed in Ref. [33], composed by a Na-TEC and a thermoelectric generator (TEG), is in order here. This is also shown in Table 3. It is clearly seen from the data in Table 3 that the performances of the hybrid Na-TEC-TEG system (row 5) are better than those of the single Na-TEC (row 4) but worse than those of the Na-TEC-BHE system (row 3). Again, the advantage of a bottoming Brayton against a bottoming thermoelectric generator device is clear.

The decrease in efficiency when the solar component is considered (comparing rows 1 and 3 , and 2 and 4 ) is expected, since the power output is maintained but the radiation losses from the solar collector provoke the need of an additional extra heat input; meanwhile in the analysis excluding the solar component, the radiation losses in the heat input are not considered. In both cases the efficiency drops are around $30 \%$.

\section{Multiobjective and multiparametric optimization}

All above results have been obtained on the parametric optimization of the power and efficiency obtained with the proposed model in Section 2. A complementary and useful information of the optimal functions and parameters could be obtained based on numerical multi-objective and multi-parametric optimization 
methods giving the so-called Pareto front (which gives the best compromise among desirable quantities and where a further improvement in one function involves the degrading of the rest) and the corresponding optimal set of parameters [58]. The results obtained are shown in Fig. 7. The optimization variables are $J, x, T_{C}$, and $C$, and the objective functions are the efficiency, POD and efficient power density. The Pareto front is obtained by considering the energetics of the overall system and comparing with the situation in which only the subsystems are optimized (solar, Na-TEC and BHE).

If the goal is to optimize the solar component, the possible configurations in the energetic space and in the variables space are obtained as plotted in Fig. 7(a-c). As expected, the POD and efficiency are directly linked to $C$, and also, there is a noticeable preference for large values of $J$ and $T_{C}$ [see Fig. 7 (b)]. The variable $x$ is not directly linked with the optimization of the solar component (notice that near points in Fig. 7 (b) are not necessarily near in Fig. 7 (c), however, the values of $x$ and $A_{A} / A_{E}$ are constrained [see Fig. 7 (c)]. In brief, even when only one part of the system is optimized, there are effects on the variables that are not associated to that subsystem.

In Fig. 7 (d) the Pareto front of the isolated Na-TEC and BHE components are compared with the Pareto front of the coupled system. For the Na-TEC system optimization the variable $x$ is not constrained but $J$ and $T_{C}$ are linked [see Fig. 7 (e)]. The BHE performance is strongly dependent on the $T_{C}$-values and one value of $x$ (approx. 1.57) and $J$ (around $5.37 \times 10^{5} \mathrm{~A} / \mathrm{m}^{2}$ ). This is the component with the strongest constraints but $x$ remains almost constant (approx. $1.57 \pm 0.015$ ). All together, these results endorse the observed asymptotic behavior in Fig. 4 of $J, x$, and $T_{C}$ for relative high $C$ values. It also allows us to deepen into the influence of the optimization variables, which are not only linked to the subsystem from which they come from, showing that the benefit of each component is not entirely for the benefit of the whole. In particular, note this feature, in the very different values of the concentration ratio, C, for each subsystem and the overall system in Fig. 7 (f).

\section{Conclusions}

A more realistic integrating device comprising a solarized sodium cell with a bottoming Brayton cycle has been modeled, taking into account losses coming from external thermal radiation, heat leak of the integrating system and irreversible losses inside each subsystem. Four generic and main results are listed as follows:

(i) Both the maximum efficiency and maximum power density regimes have been characterized and numerically obtained for the different solar concentration ratios. While the first one requires very high concentration ratios, the second one is feasible at moderate and technically accessible values.

(ii) The influences of a few critical parameters including the solar concentration ratio, thickness of the BASE, current density of the converter, and adiabatic temperature ratio (or pressure ratio) of the BHE on the performances of the whole device are studied. The optimum surfaces of solar absorber and electrolyte are determined for different solar concentration ratios.

(iii) The challenging problem of considering both the POD and efficiency, is solved by introducing the trade-off figure of merit $Z=p \eta$. It gives a compromise between above two regimes as it provides efficiencies near the maximum efficiency regime and powers slightly lower than those of the maximum power performance regime.

(iv) The proposed hybrid device is found to be a high efficient energy converter of solar radiation under the presented parametric optimization. These findings are endorsed by the Pareto front results deduced by using multi-objective and multi-parametric methods.

\section{CRediT authorship contribution statement}

Wanli Peng: Conceptualization, Methodology, Software, Formal analysis, Writing - original draft, Writing - review \& editing. Julian Gonzalez-Ayala: Software, Formal analysis, Writing - review \& editing. Guozhen Su: Validation, Formal analysis, Visualization. Jincan Chen: Resources, Conceptualization, Writing - review \& editing, Supervision, Data curation. Antonio Calvo Hernández: Resources, Conceptualization, Writing - review \& editing, Supervision, Data curation.

\section{Declaration of competing interest}

The authors declare that they have no known competing financial interests or personal relationships that could have appeared to influence the work reported in this paper.

\section{Acknowledgments}

China Scholarship Council under the State Scholarship Fund (No. 201806310020), People's Republic of China.

\section{References}

[1] A. Kasaeian, E. Bellos, A. Shamaeizadeh, C. Tzivanidis, Solar-driven polygeneration systems: recent progress and outlook, Appl. Energy 264 (2020) 114764.

[2] I. Pakere, D. Lauka, D. Blumberga, Solar power and heat production via photovoltaic thermal panels for district heating and industrial plant, Energy 154 (2018) 424-432.

[3] W. Qu, X. Xing, Y. Cao, T. Liu, H. Hong, H. Jin, A concentrating solar power system integrated photovoltaic and mid-temperature solar thermochemical processes, Appl. Energy 262 (2020) 114421.

[4] M.J. Santos, C. Miguel-Barbero, R.P. Merchán, A. Medina, A.C. Hernández, Roads to improve the performance of hybrid thermosolar gas turbine power plants: working fluids and multi-stage configurations, Energy Convers. Manag. 165 (2018) 578-592.

[5] R.P. Merchán, M.J. Santos, A. Medina, A.C. Hernández, Hybrid Brayton thermosolar systems: thermodynamic prediction of annual efficiencies and emissions, Energy Convers. Manag. 134 (2017) 314-326.

[6] R.P. Merchán, M.J. Santos, A. Medina, A.C. Hernández, Thermodynamic model of a hybrid Brayton thermosolar plant, Renew. Energy 128 (2018) 473-483.

[7] R.P. Merchán, M.J. Santos, I. Heras, J. Gonzalez-Ayala, A. Medina, A.C. Hernández, On-design pre-optimization and off-design analysis of hybrid Brayton thermosolar tower power plants for different fluids and plant configurations, Renew. Sustain. Energy Rev. 119 (2020) 109590.

[8] J. Chen, Optimization of a solar-driven heat engine, J. Appl. Phys. 72 (1992) 3778-3780.

[9] B. Kongtragool, S. Wongwises, A review of solar-powered Stirling engines and low temperature differential Stirling engines, Renew. Sustain. Energy Rev. 7 (2003) 131-154.

[10] L. Yaqi, H. Yaling, W. Weiwei, Optimization of solar-powered Stirling heat engine with finite-time thermodynamics, Renew. Energy 36 (2011) 421-427.

[11] G. Segev, Y. Rosenwaks, A. Kribus, Loss mechanisms and back surface field effect in photon enhanced thermionic emission converters, J. Appl. Phys. 114 (2013), 044505.

[12] S. Su, H. Zhang, X. Chen, J. Kang, J. Chen, Parametric optimum design of a photon-enhanced thermionic solar cell, Sol. Energy Mater. Sol. Cells 117 (2013) 219-224.

[13] S. Su, Y. Wang, T. Liu, G. Su, J. Chen, Space charge effects on the maximum efficiency and parametric design of a photon-enhanced thermionic solar cell, Sol. Energy Mater. Sol. Cells 121 (2014) 137-143.

[14] Q. Dong, T. Liao, Z. Yang, X. Chen, J. Chen, Performance characteristics and parametric choices of a solar thermophotovoltaic cell at the ME, Energy Convers. Manag. 136 (2017) 44-49.

[15] N.P. Harder, P. Würfel, Theoretical limits of thermophotovoltaic solar energy conversion, Semicond. Sci. Technol. 18 (2003) 151.

[16] E. Rephaeli, S. Fan, Absorber and emitter for solar thermo-photovoltaic systems to achieve efficiency exceeding the Shockley-Queisser limit, Optic Express 17 (2009) 15145-15159.

[17] H. Scherrer, L. Vikhor, B. Lenoir, A. Dauscher, P. Poinas, Solar thermolectric 
generator based on skutterudites, J. Power Sources 115 (2003) 141-148.

[18] R. Amatya, R.J. Ram, Solar thermoelectric generator for micropower applications, J. Electron. Mater. 39 (2010) 1735-1740.

[19] D. Kraemer, B. Poudel, H.P. Feng, J.C. Caylor, B. Yu, X. Yan, Y. Ma, X. Wang, D. Wang, A. Muto1, K. McEnaney, M. Chiesa1, Z. Ren, G. Chen, High-performance flat-panel solar thermoelectric generators with high thermal concentration, Nat. Mater. 10 (2011) 532.

[20] L.L. Baranowski, G.J. Snyder, E.S. Toberer, Concentrated solar thermoelectric generators, Energy Environ. Sci. 5 (2012) 9055-9067.

[21] T. Cole, Thermoelectric energy conversion with solid electrolytes, Science 221 (1983) 915-920.

[22] M.L. Underwood, R.M. Williams, M.A. Ryan, B. Jefferies-Nakamura, D. O'Connor, An AMTEC vapor-vapor, series connected cell, AIP Conf. Proc. 246 (1992) 1331-1337.

[23] M.A.K. Lodhi, M.S. Chowdhury, The role of electrodes in power degradation of AMTEC: analysis and simulation, J. Power Sources 96 (2001) 369-375.

[24] M.A.K. Lodhi, A. Daloglu, Performance parameters of material studies for AMTEC cell, J. Power Sources 85 (2000) 203-211.

[25] S.Y. Wu, L. Xiao, Y. Cao, Y.R. Li, A parabolic dish/AMTEC solar thermal power system and its performance evaluation, Appl. Energy 87 (2010) 452-462.

[26] E. Chivington, T. Hershey, M. Schuller, A solar heated AMTEC spacecraft power system, Intersoc. Energy Convers. Eng. Conf. (1994) 3814.

[27] G. Johnson, M.E. Hunt, W.R. Determan, P.A. HoSang, J. Ivanenok, M. Schuller, Design and integration of a solar AMTEC power system with an advanced global positioning satellite, IEEE Aero. Electron. Syst. Mag. 12 (1997) 33-40.

[28] K. Tanaka, Concept design of solar thermal receiver using alkali metal thermal to electric converter (AMTEC), Curr. Appl. Phys. 10 (2010) S254-S256.

[29] T.J. Hendricks, C. Huang, High-performance radial AMTEC cell design for ultrahigh-power solar AMTEC systems, J. Sol. Energy Eng. 122 (2000) 49-55.

[30] W. Peng, W. Li, X. Chen, G. Su, J. Chen, Optimum operation states and parametric selection criteria of an updated solar-driven AMTEC, Renew. Energy 141 (2019) 209-216.

[31] S.Y. Wu, G. Guo, L. Xiao, Z.L. Chen, A new AMTEC/TAR hybrid system for power and cooling cogeneration, Energy Convers. Manag. 180 (2019) 206-217.

[32] S.Y. Wu, Y.C. Zhang, H. Yang, L. Xiao, Performance evaluation and parametric analysis of AMTEC/TEG hybrid system, Energy Convers. Manag. 154 (2017) $118-126$.

[33] W. Peng, W. Li, Z. Ye, G. Su, J. Chen, Parametric design strategies of an updated alkali metal thermoelectric converter-thermoelectric generator system operating at optimum states, Energy Convers. Manag. 182 (2019) 53-59.

[34] W. Peng, J. Gonzalez-Ayala, J. Guo, J. Chen, A.C. Hernández, An alkali metal thermoelectric converter hybridized with a Brayton heat engine: parametric design strategies and energetic optimization, J. Clean. Prod. 260 (2020) 120953.

[35] J.M.M. Roco, S. Velasco, A. Medina, A.C. Hernández, Optimum performance of a regenerative Brayton thermal cycle, J. Appl. Phys. 82 (1997) 2735-2741.

[36] Y. Ust, A. Safa, B. Sahin, Ecological performance analysis of an endoreversible regenerative Brayton heat-engine, Appl. Energy 80 (2005) 247-260.

[37] Y. Ust, B. Sahin, A. Kodal, I.H. Akcay, Ecological coefficient of performance analysis and optimization of an irreversible regenerative-Brayton heat engine, Appl. Energy 83 (2006) 558-572.

[38] A. Durante, G. Pena-Vergara, P.L. Curto-Risso, A. Medina, A.C. Hernández, Thermodynamic simulation of a multi-step externally fired gas turbine powered by biomass, Energy Convers. Manag. 140 (2017) 182-191.

[39] J. Guo, L. Cai, J. Chen, Y. Zhou, Performance evaluation and parametric choice criteria of a Brayton pumped thermal electricity storage system, Energy 113 (2016) 693-701.

[40] P. Sharan, T. Neises, C. Turchi, Optimal feed flow sequence for multi-effect distillation system integrated with supercritical carbon dioxide Brayton cycle for seawater desalination, J. Clean. Prod. 196 (2018) 889-901.

[41] C.B. Vining, R.M. Williams, M.L. Underwood, M.A. Ryan, J.W. Suitor, Reversible thermodynamic cycle for AMTEC power conversion, J. Electrochem. Soc. 140 (1993) 2760-2763.

[42] M. Elzouka, S. Ndao, Towards a near-field concentrated solar thermophotovoltaic microsystem: Part I-Modeling, Sol. Energy 141 (2017) 323-333.

[43] http://rredc.nrel.gov/solar/spectra/am1.5/.

[44] A. Limia, J.M. Ha, P. Kottke, A. Gunawan, A.G. Fedorov, S.W. Lee, S.K. Yee, A dual-stage sodium thermal electrochemical converter (Na-TEC), J. Power Sources 371 (2017) 217-224.

[45] Q. Wang, W. Yao, H. Zhang, X. Lu, Analysis of the performance of an alkali metal thermoelectric converter (AMTEC) based on a lumped thermalelectrochemical model, Appl. Energy 216 (2018) 195-211.

[46] W. Peng, X. Zhang, Z. Ye, J. Chen, Optimum operation states and parametric selection criteria of an updated alkali metal thermal electric converter, Energy Convers. Manag. 168 (2018) 230-236.

[47] M.A.K. Lodhi, P. Vijayaraghavan, A. Daloglu, An overview of advanced space/ terrestrial power generation device: AMTEC, J. Power Sources 103 (2001) 25-33.

[48] J.M. Tournier, M.S. El-Genk, M. Schuller, P. Hausgen, An analytical model for liquid-anode and vapor-anode AMTEC converters, AIP Conf. Proc. 387 (1997) $1543-1552$.

[49] J.M. Tournier, M.S. El-Genk, An electric model of a vapour anode, multitube alkali-metal thermal-to-electric converter, J. Appl. Electrochem. 29 (1999) $1263-1275$

[50] C.A. Spence, M. Schuller, T.R. Lalk, Development, evaluation, and design applications of an NA-TEC converter model, AIP Conf. Proc. 654 (2003) 685-700.

[51] J. Horlock, Advanced Gas Turbine Cycles, Pergamon, Oxford, 2003.

[52] C.Y. Cheng, Ecological optimization of an irreversible Brayton heat engine, J. Phys. D Appl. Phys. 32 (1999) 350.

[53] Y. Zhang, C. Ou, B. Lin, J. Chen, The regenerative criteria of an irreversible Brayton heat engine and its general optimum performance characteristics, J. Energy Resour. Technol. 128 (2006) 216-222.

[54] S. Sánchez-Orgaz, A. Medina, A.C. Hernández, Thermodynamic model and optimization of a multi-step irreversible Brayton cycle, Energy Convers. Manag. 51 (2010) 2134-2143.

[55] J.W. Stucki, The optimal efficiency and the economic degrees of coupling of oxidative phosphorylation, Eur. J. Biochem. 109 (1980) 269-283.

[56] S. Levario-Medina, G. Valencia-Ortega, L.A. Arias-Hernandez, Thermal optimization of Curzon-Ahlborn heat engines operating under some generalized efficient power regimes, Eur. Phys. J. Plus 134 (2019) 348.

[57] M.T. Islam, N. Huda, A.B. Abdullah, R. Saidur, A comprehensive review of stateof-the-art concentrating solar power (CSP) technologies: current status and research trends, Renew. Sustain. Energy Rev. 91 (2018) 987-1018.

[58] K. Deb, Multi-objective Optimization Using Evolutionary Algorithms, vol. 16, John Wiley \& Sons, 2001. 